\section{VARIATION IN BEARING CAPACITY OF SOIL DUE tO Changes in Water table Depth in Dhaka,} BANGLADESH

\author{
Ahanaf Tahmid, Siam Junaed, A S M Fahad Hossain* \\ Department of Civil Engineering, Ahsanullah University of Science and \\ Technology (AUST), Dhaka, Bangladesh.
}

Article history Received 15 February 2021 Received in revised form 26 April 2021 Accepted 28 April 2021 Published online 30 July 2021

*Corresponding author fahad.ce@aust.edu

\begin{abstract}
The bearing capacity of the soil is a significant topic in geotechnical engineering, especially in foundation engineering, as the stability of any foundation depends on it. A structure with a very sound design may collapse standing on poor soil with low bearing capacity. As the depth of the water table increases, the ultimate bearing capacity of soil increases. The effect of an increase in depth on safe bearing capacity is predominant due to an increase in surcharge weight. The higher the water table, the lesser is as far as possible and strength of the soil. In this research, soil test reports of different locations of Dhaka city were collected, and the bearing capacity of the soil was calculated by Terzaghi's method based on a fixed foundation depth with a variation of water table depth. Bearing capacity was compared with the depth of the water table in graphical format and it was seen that bearing capacity of soil increases with the increase of water table depth.
\end{abstract}

Keywords: Bearing capacity; shallow foundation; water table depth; factor of safety

(C) 2021 Penerbit UTM Press. All rights reserved

\subsection{INTRODUCTION}

Inconspicuous components are essential when assembling a sound structure establishment that may withstand water and control clamminess. Establishment fixes are regularly confounded and costly. So, constructing a foundation correctly for the first time is incredibly crucial. The designing and planning of a solid foundation particularly captivated the depth of the ground water level at the location. As we all know that, Dhaka is that the capital of Bangladesh. It's a country of six seasons depending on climate: summer, rain, autumn, late autumn, winter and spring. Groundwater level varies with different seasons. For the variation of water table depth, the bearing limit of soil may change, which is why choosing the placement. The lower the depth, the more challenging it's to form a robust foundation because the potential of the soil is proscribed. It's the best stress that a given soil can endure without collapsing, as far as bearing capacity is anxious. This paper focuses on the effect of the formation with the variation in bearing capacity of the soil and its ease to construct general foundations on the benefit of bearing capacity. Of the multitude of standards, the load-bearing limit of the dirt to help the load getting through its unit region is vital [1]. Universal bearing limit hypotheses for deciding the general bearing limit of shallow establishments propose that the bearing layer is homogeneous and boundless. However, layer soils are mainly present in natural occurrence, which contradicts the theory. A strong covering can be found at shallow profundity, or the soil might be graded and have different shear strength boundaries. The shear pattern is skewed and bearing capacity in weaker or stronger material depends on the degree of the rupture surface in such situations [2]. Various methods for the analysis of soil bearing capacity have been developed by scientists such as Terzaghi, Vesic, Meyerhof, Hansen, and others. The key factors that influence a definitive bearing limit are the soil condition, the width of the establishment, the heaviness of the soil in the shear zone, and the additional charge. In addition to the soil properties, the depth of the foundation, the difference at the water table at the base of the foundation, the eccentricity of the loading process governs the final and secure loading capacity of the soil [3]. Terzaghi (1943) proposed the first semiempirical equation for calculating the ultimate bearing ability of shallow footings. Utilizing the overlay hypothesis demonstrated the impacts of soil cohesion, the point of inner erosion, overabundance (soil over the base level), soil unit weight, and base width on a definitive bearing pressure. Afterward, Hansen and Brinch developed the bearing capacity equation as a 
thought that represented the type of the establishment and the tendency of the load [4].

This work aims to concentrate on the variety in bearing limit of soil because of changes in water table profundity. The work was intended to examine the properties of better places soil test reports gathered to assure ultimate and safe bearing limit of the soil utilizing Terzaghi.

\subsection{METHODOLOGY}

In the research, soil rest reports were collected from various sites of Dhaka city. Different locations are shown in Table 1, and the site area map is shown in Figure 1. The depth and width of the foundation were fixed to eight (8) feet and ten (10) feet. The water table was varied from ground level to a depth of Df+B as water effects till that depth. Also, the factor of safety was considered here three (3) after considering that the soil's bearing capacity was calculated by Terzaghi equation (for square footing) with water table modification at Table-2. Here, values of cohesion (c) and angle of internal friction ( $\Phi)$ were taken from soil test reports of the locations, and $\mathrm{Nc}, \mathrm{Nq}$, and $\mathrm{N} \gamma$ values were taken from Principles of Geotechnical Engineering by B. M. Das, 7th edition.

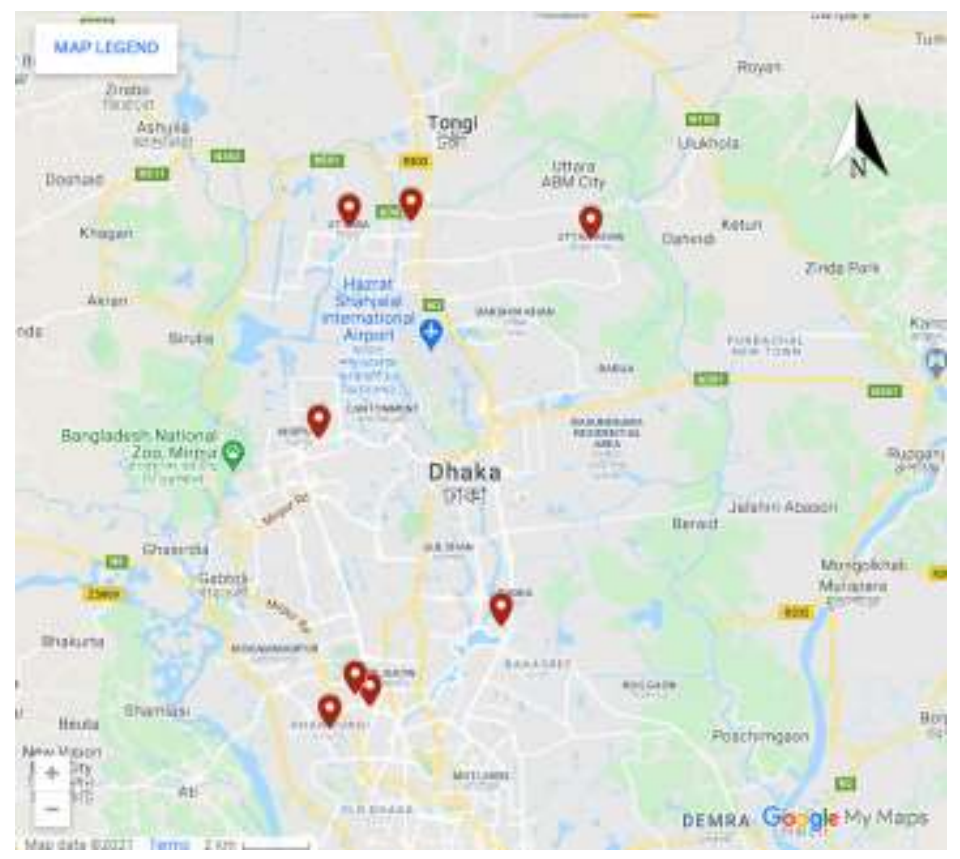

Figure 1 Site Area Map (Google Map)

Table 1 Selected Locations

\begin{tabular}{|c|c|c|c|c|c|}
\hline Site No & Area & $\begin{array}{c}\text { Cohesion, } \\
\text { C (psf) }\end{array}$ & $\begin{array}{c}\text { Angle of } \\
\text { friction, } \\
\phi\end{array}$ & $\begin{array}{c}\text { Moist unit } \\
\text { weight } \\
\text { gsat }_{\text {(pcf) }}\end{array}$ & $\begin{array}{c}\text { Saturated unit } \\
\text { weight } \\
\text { g (pcf) }\end{array}$ \\
\hline 1 & Uttara Sector 9 & 2396.8 & 0 & 112 & 133 \\
\hline 2 & Uttarkhan & 0 & 32 & 119 & 136 \\
\hline 3 & West Razabazar & 1500 & 30 & 111 & 130 \\
\hline 4 & Uttara 2 & 1261 & 0 & 110 & 131 \\
\hline 5 & Panthapath & 421.12 & 0 & 108 & 127 \\
\hline 6 & Merul Badda & 250 & 0 & 112 & 133 \\
\hline 7 & Dhanmondi & 1740 & 0 & 108 & 125 \\
\hline 8 & Kalshi & 250.6 & 27 & 105 & 122 \\
\hline
\end{tabular}

The following equation can be used both for cohesionless and

$$
q u l t=1.3 \mathrm{CN} c+q N q+0.4 B \gamma N \gamma
$$


Were,

$\mathrm{c}=$ Cohesion (ksf); $\mathrm{q}=$ The overburden pressure $=\gamma D f(\mathrm{ksf}) ; \mathrm{B}=$ Width of the foundation (ft); $\boldsymbol{\gamma}=$ Unit weight of soil (kcf); $D f=$ Depth of foundation (ft); qult = Ultimate bearing capacity of soil (ksf); $\mathrm{Nc}, \mathrm{Nq}$ and $\mathrm{N} \gamma$ are non-dimensional bearing capacity factors and functions only of the angle of internal friction, $\Phi$.

Terzaghi equation (equation 1) provides an absolute bearing limit dependent on the supposition that the water table is found well underneath the establishment. In any case, if the water table is near the establishment, the bearing limit will diminish because of the impact of the water table; thus, some alteration of the bearing limit condition (Terzaghi) will be significant. The qualities which will be altered are:

1. (q for soil over the establishment) in the condition.

2. ( $\gamma$ for the fundamental soil) in the condition.

There are three cases as per placement of water table:

Case 1: The water table is found with the goal that $0 \leq \mathrm{D} 1 \leq \mathrm{Df}$ as demonstrated in the accompanying figure 2 .

The factor, $q$ in the bearing limit condition will take the accompanying structure: (For the soil over the establishment)

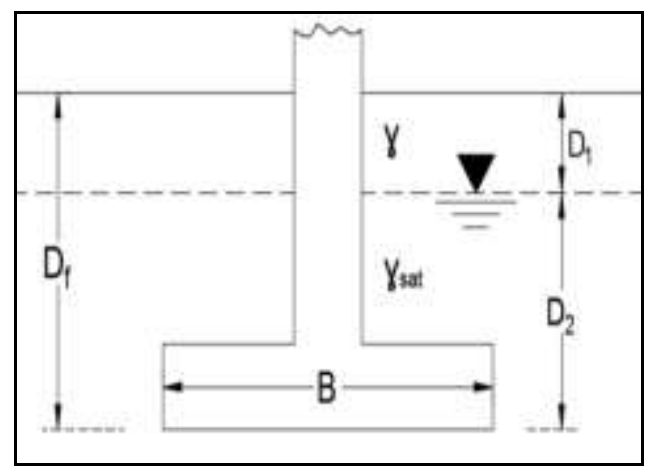

Figure 2: For Case 1

Case 3: The water table is found so $d \geq B$; for this situation, the water table is accepted to have no impact on the ultimate bearing limit.

\subsection{EFFECT OF WATER TABLE ON BEARING CAPACITY}

The improvement in the soil's dampness content decides the soil's properties. Likewise, when the soil is lowered, the ability to help the load coming over the unit region is brought down when the water table is over the base of the footing. The reduced weight is utilized to gauge the extra charge for the soil beneath the water table. The progressions to the water table are added to get to the soil's ultimate bearing limit. The estimations of safe bearing limits are determined utilizing the safety factor (3) and the rectangular balance strategy for Terzaghi. The common example of groundwater stream is changed either deliberately by human action, either by emptying water out of wells or by redirecting water courses, or

$$
q=D 1 \times \gamma+D 2 \times(\gamma s a t-\gamma w)
$$

The factor, $\gamma$ in the bearing limit condition will take the accompanying structure: (For the soil under the establishment)

$$
\gamma=\gamma^{\prime}=\gamma s a t-\gamma w
$$

Case 2: The water table is found so $0 \leq d \leq B$ as demonstrated in Figure 3.

The factor, $q$ in the bearing limit condition will take the accompanying structure: (For the soil over the establishment)

$$
q=D f \times \gamma
$$

The factor, $\gamma$ in the bearing limit condition will take the accompanying structure: (For the dirt under the establishment)

$$
\gamma=\gamma \mapsto=\gamma^{\prime}+d \times\left(\gamma-\gamma^{\prime}\right) / B
$$

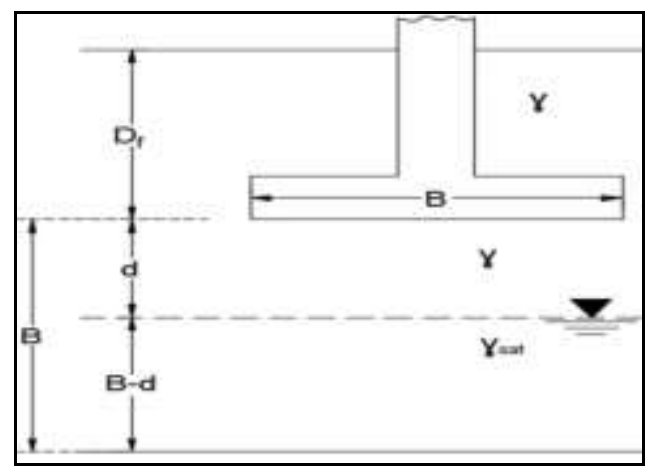

Figure 3: For Case 2

coincidentally by changes in land utilization. The water level in the spring will diminish if the pace of deliberation from a spring is excessively high and surpasses the measure of water revived from precipitation. This raises the expense of siphoning and assists with diminishing the yield of individual boreholes simultaneously. However, it can likewise impact the progression of waterways and streams where groundwater uphold is given. An excessive amount of new water might be a worry too. In damp winter, expanding volumes of groundwater will spill into basements and low-lying fields. This type of flooding issue can be a long haul because groundwater seems to react gradually.

Devastation from groundwater flooding issues is generally our own deficiency. Land that definitely defenseless against flooding is based on, and flood basements with goods and fittings are transformed into living space. Establishments of any sort should be based on a stable sub-landscape. Without having some early notification of such disintegration, water will dissolve man-made materials. The high-water substance of the earth permits the vital segments of the base to get sloppy, at 
that point they are blended. For instance, solid will retain any water, it is consistent, and the straightforward cement without some type of water repellant the blend separates, and if steel poles are embedded to fortify the strength, they can disintegrate from erosion and at last breakdown. Water levels (the water table) are resolved in and around a structure before development starts. The higher the table (water level), the more troublesome it is to burrow down to a dry one. Thus, a house almost a waterway will have establishments 10 feet down, contain more prominent degrees of water pesticides and have a greater water film adds to the first cost of developing comparative with a position high, away from water levels.

The essential guideline of bearing limit depends on the reason that the water table is far beneath and doesn't strife with the establishment. Be that as it may, the presence of the water table at the profundity of the establishment impacts the nature of the soil. In the examination, the unit weight of the soil to be considered within sight of a water table is the lowered thickness and not the dry thickness. The lowered thickness would then be utilized in the second and third terms of the force condition to comprehend the results of the water table.

\subsection{ANALYSIS RESULTS}

Calculated allowable soil bearing capacity for different water table depths for an $8 \mathrm{ft}$ deep foundation is given in Table 2. Figures $4(\mathrm{a}-\mathrm{h})$ are shown a plot of allowable bearing capacity with the depth of GWL generated from the table's data is provided to observe the change in soil bearing capacity with the change of water table depth.

Table 2 Allowable Bearing capacity of soil for different water level depth.

\begin{tabular}{|c|c|c|c|c|c|c|c|c|}
\hline Water Table & \multicolumn{7}{|c|}{ Allowable Bearing Capacity, Tsf } \\
\cline { 2 - 9 } Depth, Ft & Site 1 & Site 2 & Site 3 & Site 4 & Site 5 & Site 6 & Site 7 & Site 8 \\
\hline 0 & 2.73 & 3.68 & 13.36 & 1.47 & 0.54 & 0.36 & 1.99 & 2.96 \\
\hline 1 & 2.73 & 3.87 & 13.50 & 1.48 & 0.55 & 0.37 & 1.99 & 3.06 \\
\hline 2 & 2.74 & 4.06 & 13.64 & 1.48 & 0.55 & 0.37 & 2.01 & 3.17 \\
\hline 3 & 2.75 & 4.25 & 13.79 & 1.50 & 0.56 & 0.38 & 2.01 & 3.28 \\
\hline 4 & 2.75 & 4.45 & 13.93 & 1.50 & 0.57 & 0.38 & 2.02 & 3.39 \\
\hline 5 & 2.76 & 4.64 & 14.07 & 1.50 & 0.57 & 0.39 & 2.03 & 3.49 \\
\hline 6 & 2.76 & 4.83 & 14.21 & 1.51 & 0.58 & 0.40 & 2.03 & 3.60 \\
\hline 7 & 2.77 & 5.03 & 14.35 & 1.52 & 0.59 & 0.40 & 2.04 & 3.71 \\
\hline 8 & 2.78 & 5.22 & 14.49 & 1.52 & 0.59 & 0.41 & 2.05 & 3.82 \\
\hline 9 & 2.78 & 5.29 & 14.54 & 1.52 & 0.59 & 0.41 & 2.05 & 3.85 \\
\hline 10 & 2.78 & 5.36 & 14.59 & 1.52 & 0.59 & 0.41 & 2.05 & 3.88 \\
\hline 11 & 2.78 & 5.44 & 14.64 & 1.52 & 0.59 & 0.41 & 2.05 & 3.91 \\
\hline 12 & 2.78 & 5.51 & 14.69 & 1.52 & 0.59 & 0.41 & 2.05 & 3.94 \\
\hline 13 & 2.78 & 5.58 & 14.74 & 1.52 & 0.59 & 0.41 & 2.05 & 3.97 \\
\hline 14 & 2.78 & 5.65 & 14.78 & 1.52 & 0.59 & 0.41 & 2.05 & 4.00 \\
\hline 15 & 2.78 & 5.73 & 14.83 & 1.52 & 0.59 & 0.41 & 2.05 & 4.04 \\
\hline 16 & 2.78 & 5.80 & 14.88 & 1.52 & 0.59 & 0.41 & 2.05 & 4.07 \\
\hline 17 & 2.78 & 5.87 & 14.93 & 1.52 & 0.59 & 0.41 & 2.05 & 4.10 \\
\hline 18 & 2.78 & 5.94 & 14.98 & 1.52 & 0.59 & 0.41 & 2.05 & 4.13 \\
\hline & & & & & & & & \\
\hline
\end{tabular}

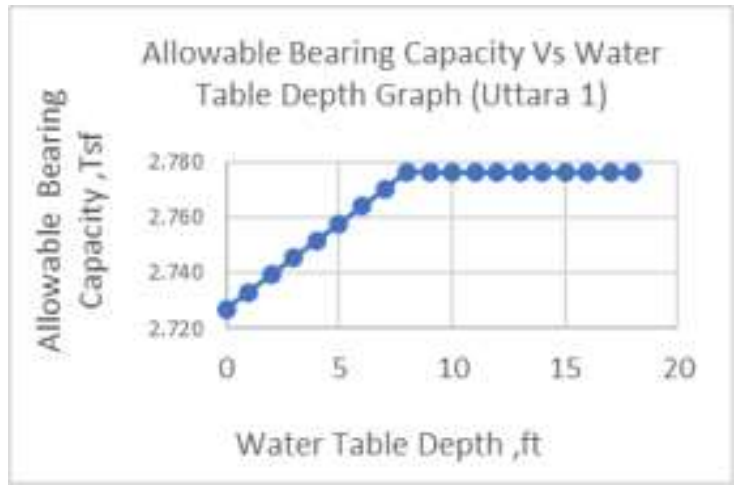

(a) Site 1

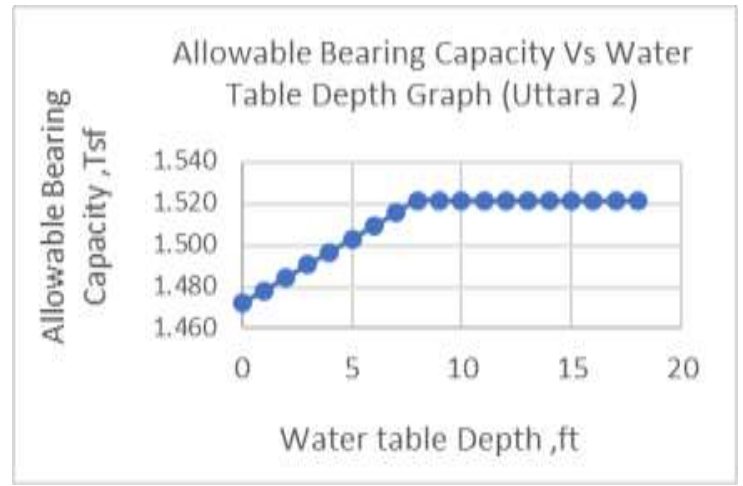

(b) Site 2 


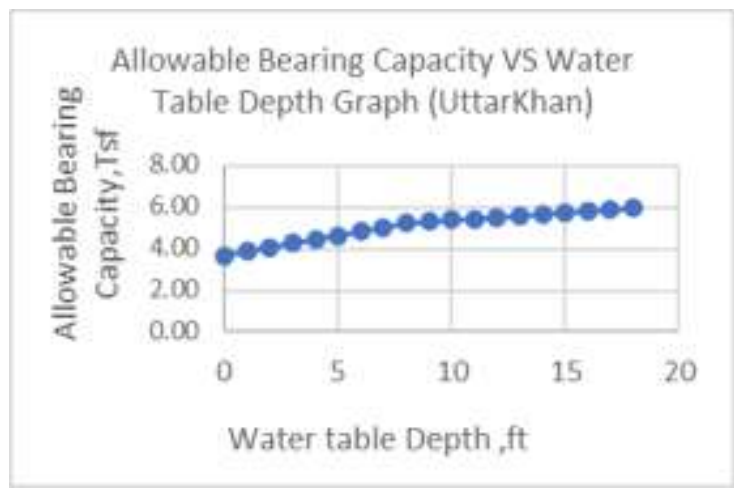

(c) Site 3

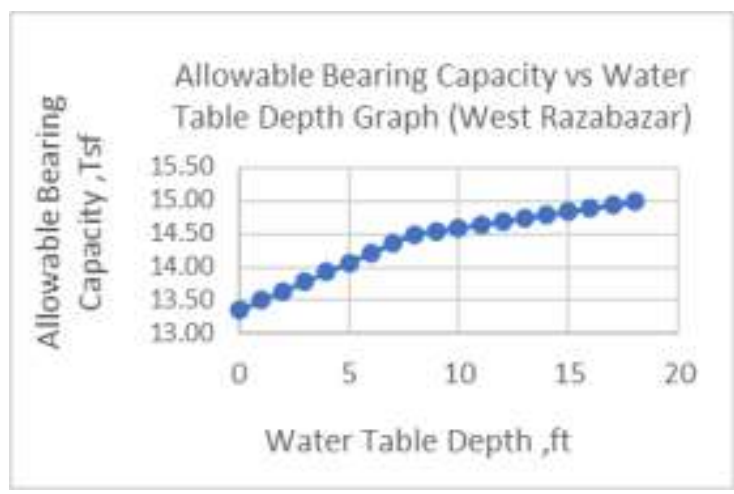

(e) Site 5

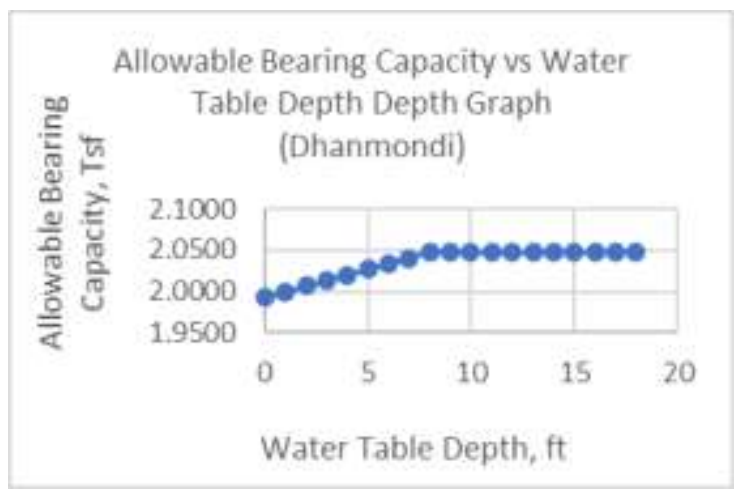

(g) Site 7

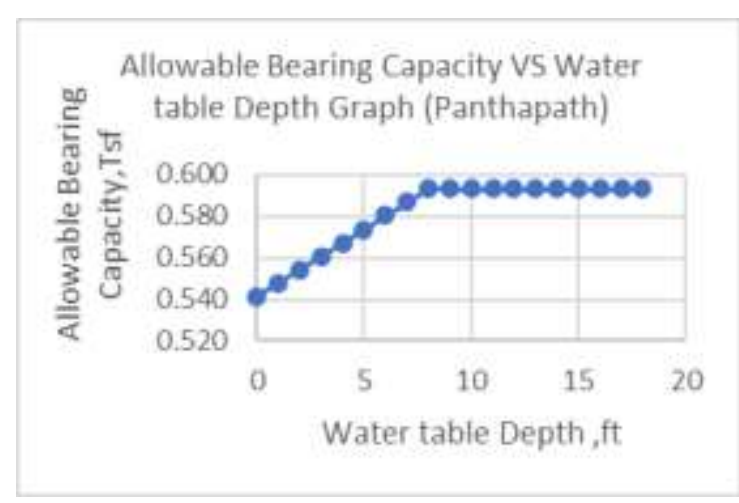

(d) Site 4

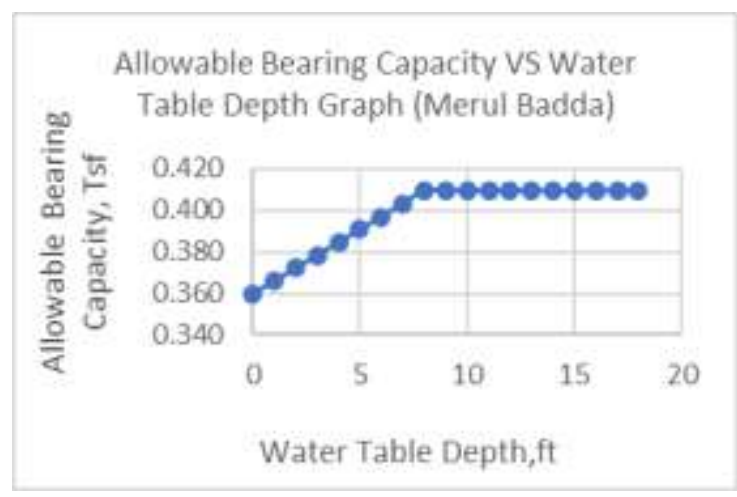

(f) Site 6

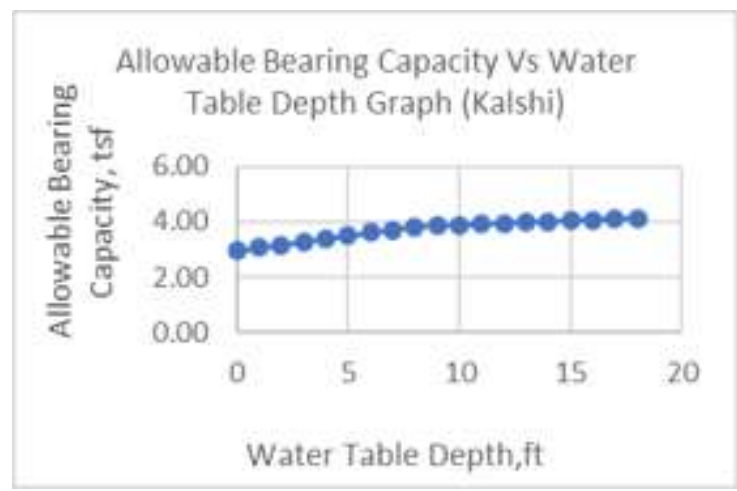

(h) Site 8

Figure 4: Allowable Bearing Capacity VS. Water Table Depth Graph

\subsection{CONCLUSION AND RECOMMANDATIONS}

As the water table has many effects on the properties and behavior of soil and all loads from the superstructures are transmitted to the foundation soil, the impact of water table depth on the bearing capacity needs to be known as the water table varies seasonally. The objective of the research was to find out the changes of bearing capacity with change in water table and it was found that: with the increment of water table profundity, the bearing limit of soil is also incremented. The authors recommends that:
- The water table variation may be calculated by using others method.

- The water table variation may be determined for other types of footings.

- This research is limited only in one city. So, it may be vast.

\section{References}

[1] Hansen, J, B. 1968. A Revised Extended Formula for Bearing Capacity, Danish geotechnical institute Bulletin, NO28. 
[2] Meyerhof, G G 1956. Penetration Tests and bearing capacity of cohesionless soils, Journal of the Soil Mechanics and Foundations Division. 82(1): 1-19
[3] Bowles, J, E. 1988. Foundation Analysis and Design, MC Graw Hill publications New York.

[4] Das, B, M. 1985.Principles of Geotechnical Engineering by B. M. Das, 7th edition. 